\title{
Effects of dry and mist saunas on circulatory and thermoregulatory functions in humans
}

\author{
Satoshi Iwase ${ }^{1^{\star}}$, Yuko Kawahara ${ }^{2}$, Naoki Nishimura$^{1}$, Hiroki Takada ${ }^{3}$, Mayumi Nagata ${ }^{4}$, \\ Yuki Niimi ${ }^{5}$, Chihiro Miwa ${ }^{6}$ \\ ${ }^{1}$ Department of Physiology, Aichi Medical University, Nagakute, Japan; * Corresponding Author: s iwase@,nifty.com \\ ${ }^{2}$ Group of Home Systems \& Appliance R\&D, Department of Home Systems \& Appliance Sales, Toho Gas Co. Ltd., Nagoya, Japan \\ ${ }^{3}$ Department of Human \& Artificial Intelligent Systems, Graduate School of Engineering, University of Fukui, Fukui, Japan \\ ${ }^{4}$ Plumbing Fixtures Technology Research Institute, Kitchen \& Plumbing Fixtures Company, LIXIL Corporation, Tokoname, Japan \\ ${ }^{5}$ Department of Neurology, Tsushima Municipal Hospital, Tsushima, Japan \\ ${ }^{6}$ Aichi Medical College for Physical Therapy and Occupational Therapy, Kiyosu, Japan
}

Received 7 December 2012; revised 6 January 2013; accepted 14 January 2013

\begin{abstract}
To test the hypothesis that mist sauna is a safer way of bathing than dry sauna, we compared changes in circulatory and thermoregulatory functions during $\mathbf{1 0}$ min sauna bathing in mist sauna at $40^{\circ} \mathrm{C}$ with relative humidity of $100 \%$, and in dry sauna by infrared ray at $70^{\circ} \mathrm{C}$ with relative humidity of $15 \%$. Subjects were seven healthy young men aged $29 \pm 6$ yrs (mean \pm SD). We measured blood pressure, heart rate, skin temperatures at chest, forearm, thigh, and leg, tympanic temperature (Tty) by thermistors, skin blood flow at forearm by laser Doppler flowmetry, and sweat rate by ventilated capsule method at 1 min intervals throughout the experiment. Total sweating and change of hematocrit were also measured for dehydration analysis. Blood pressure was elevated more and changes in heart rate and total sweating were larger in dry sauna than mist. A significant hematocrit increase was observed in dry sauna bathing only. Mean skin temperature and Tty in dry sauna were elevated higher than those in mist. Heat stress of the dry sauna may be stronger than that of the mist, leading to dehydration and hypovolemia by sweating. Percent plasma volume loss was significantly larger in the dry than mist sauna. Changes in skin blood flow and sweat rate $/ \Delta$ Tty during mist sauna were significantly larger than those during dry sauna bathing despite heat stress of the mist sauna. The mist sauna bathing may thus be safer physiologically, and provide more effective vascular dilatation and sweating than the dry sauna bathing.
\end{abstract}

Keywords: Sauna Bathing; Mist Sauna; Dry Sauna;
Heat Stress; Hemodynamic Change; Thermoregulatory Function

\section{INTRODUCTION}

Sauna bathing is widely spread in Nordic and Finish countries. It has been reported that regular sauna bathing can deep clean the skin, promote weight loss, improve blood circulation, accelerate muscle recovery, relieve tension headaches, and induce a deeper and more relaxing sleep [1-4]. In addition to the traditional dry sauna bathing that heats the sauna room temperature (RT) to $70^{\circ} \mathrm{C}-100^{\circ} \mathrm{C}$, mist sauna bathing that sparges hot water into the sauna room and maintains the $\mathrm{RT}$ at $40^{\circ} \mathrm{C}-45^{\circ} \mathrm{C}$ has become prevalent in Japan.

Many investigations on dry sauna bathing have been made due to its medical availability, however, few reports has made mention on mist sauna bathing since its commitment to commercial market in 1994. Sudoh et al. [5] and Watanabe et al. [6,7] compared the dry sauna with $90^{\circ} \mathrm{C}-100^{\circ} \mathrm{C}$ RT and relative humidity $(\mathrm{RH})>20 \%$ and the mist sauna with $42^{\circ} \mathrm{C}-45^{\circ} \mathrm{C}$ RT and RH $<90 \%$. These reported that heat stress was higher in dry sauna than mist sauna and more increase in heart rate was observed, however, sweating by mist sauna was not so different from that by dry sauna bathing.

As the result of prevalence of family sauna, we could easily enjoy sauna bathing; however, too much heat load on cardiovascular system sometimes could be a risk for cerebral/myocardial infarction coupled with dehydration by sweating. We have previously compared the bathroom heating systems between forced-air heating at $29^{\circ} \mathrm{C}$ RT with RH $60 \%$ and mist heating of $31^{\circ} \mathrm{C}$ RT with RH $100 \%$, and reported that mist heating provided less dehydration, and thus it is a safer way of bathroom heating [8]. Therefore, the mist sauna bathing is likely a safer system from the viewpoint of heat stress. 
Since the effects of sauna described above are considered to be due to results of sweating, the same effects might be obtained through mist sauna bathing. The suppression of evaporative function in mist sauna bathing might comprises highly effective heating and prevention of dehydration.

In the present study, we compared the effects of dry sauna bathing with $70^{\circ} \mathrm{C}$ RT RH $15 \%$ by far infrared ray, which has been reported to have the same effect as conventional high temperature dry sauna $\left(90^{\circ} \mathrm{C}\right.$ RT RH $<$ $10 \%$ ) [9], and newly developed mist sauna bathing with $40^{\circ} \mathrm{C}$ RT RH $100 \%$, on circulatory and thermoregulatory function in humans, and examined the physiological safety of dry and mist sauna bathing. The reason for selecting $40^{\circ} \mathrm{C}$ for mist sauna is that it is the most favorable temperature for usual whole body bathing.

\section{METHODS}

\subsection{Subjects}

Subjects were seven healthy men, age: $29 \pm 6$ (24 - 39) yr old, height: $172 \pm 8 \mathrm{~cm}$, weight: $66.1 \pm 17.3 \mathrm{~kg}$, body surface area: $1.77 \pm 0.24 \mathrm{~m}^{2}$ [10], body mass index: 22.2 \pm 3.9 , (mean $\pm \mathrm{SD})$, with informed consent in a written form. They were requested to refrain from caffeinated beverages and alcoholic drinks since the evening of the previous day of the experiment. The protocol of the present study was approved by the Ethical Committee on Human Research, Aichi Medical University.

\subsection{Sauna Facilities}

The experiment was carried out from June-July, 2000, in the sauna room $(2700 \times 2600 \mathrm{~mm})$ and bath room $(1600 \times 2000 \mathrm{~mm})$. The dry sauna facility was equipped with the far-infrared heater (GSV-150R, Nissei Oval, Tokyo), and RT and RH was controlled within $69.5^{\circ} \mathrm{C} \pm$ $0.8^{\circ} \mathrm{C}$ (the globe temperature $(\mathrm{GT})$ at $72.0^{\circ} \mathrm{C} \pm 3.4^{\circ} \mathrm{C}$ ) and $15.9 \% \pm 0.2 \%$ respectively. The mist sauna facility employed hot-water membrane mist generation system (SSD-1 GR, Yamaha Living Tec, Hamamatsu), and maintained RT $39.6^{\circ} \mathrm{C} \pm 0.7^{\circ} \mathrm{C}\left(\mathrm{GT} 41.0^{\circ} \mathrm{C} \pm 0.7^{\circ} \mathrm{C}\right), \mathrm{RH}$ $100 \%$.

\subsection{Protocol of the Experiment}

Subjects were requested to come to the experiment room at 10:00, to urinate, and to wear swimming suits. Body weight was measured with the precision to $10 \mathrm{~g}$ (HW-100K, A\&D, Tokyo). Then, they were applied the electrodes, probes, and a catheter for blood sampling. After the enough rest $>30 \mathrm{~min}$ in the control room, and they sat cross-legged on the floor of the control room for $10 \mathrm{~min}$ for baseline reading. After blood sampling, they moved to the sauna room, and were exposed to dry or mist sauna in a sitting position for $10 \mathrm{~min}$. Blood was again sampled at the end of the measurement in the sauna room. Then, they moved to the control room again, received the towel dry ( $5 \mathrm{~min}$ in total), and sat quietly for $10 \mathrm{~min}$ for recovery. Again they were requested to urinate, and their urine volume and body weight were measured.

\subsection{Measurement}

Blood was sampled from a intravenous catheter with stopcock filled with heparinized saline. Red blood count, hemoglobin, and hematocrit were determined with the auto blood counter (Sysmex, Tokyo). Per cent plasma volume change was calculated from Van Beaumont formula [11]:

$$
\begin{aligned}
\% \Delta \mathrm{PV} & =\left[100 /\left(100-\mathrm{Hct}_{\mathrm{B}}\right)\right] \\
& \times\left[100\left(\mathrm{Hct}_{\mathrm{B}}-\mathrm{Hct}_{\mathrm{A}}\right) / \mathrm{Hct}_{\mathrm{A}}\right]
\end{aligned}
$$

where $\% \Delta \mathrm{PV}$ : percent change in plasma volume, Hct: hematocrit, A: after, B: before the saunas.

Stress-related hormones, noradrenalin, adrenalin, vasopressin, and cortisol were measured before and after the dry and mist saunas. To assess the metabolism, plasma free fatty acids and plasma osmolarity were also determined.

Skin temperatures were measured at the chest, upper arm, thigh, and lower leg with thermistors (Web-5000, Nihon Kohden, Tokyo), and stored in a data recorder (KS-616, Sony Precision Technology, Tokyo). Mean skin temperature was calculated from the equation of Ramanathan [12] as

$$
\mathrm{MST}=0.3 \times \mathrm{T}_{\text {chest }}+0.3 \times \mathrm{T}_{\text {arm }}+0.2 \times \mathrm{T}_{\text {thigh }}+0.2 \times \mathrm{T}_{\text {leg }}
$$

where MST: mean skin temperature $\left[{ }^{\circ} \mathrm{C}\right], \mathrm{T}_{\text {chest }}$ : chest temperature $\left[{ }^{\circ} \mathrm{C}\right], \mathrm{T}_{\text {arm }}$ : upper arm temperature $\left[{ }^{\circ} \mathrm{C}\right], \mathrm{T}_{\text {thigh }}$ : thigh temperature $\left[{ }^{\circ} \mathrm{C}\right]$, and $\mathrm{T}_{\text {leg }}$ : lower leg temperature $\left[{ }^{\circ} \mathrm{C}\right]$.

The tip of the thermistors were covered by water and heat proof pad, and pasted on the skin with surgical tape. Skin blood flow was measured by laser Doppler flowmetry (ALF 21, Advance, Tokyo), applying the probe at the forearm. Sweating was determined by ventilated capsule method (AMU-3, Fourtion, Aichi) with dry nitrogen drainage. Total sweat volume was estimated by the difference of body weight and urine volume before and after the bathing (Total sweat volume = body weight change - urine volume). For the core temperature measurement, tympanic temperature (Tty, PZL-64S, Sensor Technica, Seto) was monitored with insulation by ear pad at the ear orifice. Blood pressure was measured by oscillometric method (BP-203i, Nippon Collin, Komaki). All values were recorded and averaged in $1 \mathrm{~min}$ interval, and stored in a data recorder. 


\subsection{Statistics}

All data were expressed as mean \pm SD. Student's paired-t test was employed to compare the individual data in various conditions, and two-way repeated measures ANOVA was used for comparison between mist and dry saunas. Any p-values less than 0.05 were considered statistically significant.

\section{RESULTS}

\subsection{Changes in Blood Count, Stress-Related Hormones, and Plasma Fatty Acids and Osmolarity after Sauna Bathings}

Erythrocyte count, hemoglobin concentration and hematocrit were significantly elevated in dry sauna $(\mathrm{p}<$ 0.05 ), but not in mist sauna. Per cent change in plasma volume was significantly greater in dry sauna than mist sauna bathings ( $\mathrm{p}<0.01$, Table 1$)$.

Noradrenalin was increased significantly both after dry $(\mathrm{p}<0.05)$ and mist sauna bathings $(\mathrm{p}<0.01)$, and the increase was greater in dry sauna $(\mathrm{p}<0.05)$. Vasopressin was also significantly elevated in both after dry and mist saunas, while the difference between dry and mist sauna was not significant. Cortisol showed no significant changes after saunas (Table 2).

Plasma free fatty acids exhibited increase both after dry and mist saunas, and the increases were significantly larger in dry sauna than in mist sauna. No significant difference was observed in plasma osmolarity between before and after both dry and mist saunas (Table 3).

\subsection{Changes in Blood Pressure (Figure 1)}

Systolic pressure by oscillometric method in $1 \mathrm{~min}$ interval showed significant increases from the baseline level at 1, 9, and $10 \mathrm{~min}$ after the sauna entry, and $0 \mathrm{~min}$ at the recovery in dry sauna bathing, and only 4 min after sauna entry in mist sauna bathing. Diastolic pressure exhibited significant increases in 1 min after the sauna entry, 2 min after the recovery, and significant decreases in 2, 5 - $7 \mathrm{~min}$ after the sauna exit during recovery in dry sauna bathing. In mist sauna bathing, significant increases was observed in 1 min after the sauna entry, significant decreases were recorded in $6 \mathrm{~min}$ after the sauna entry, and 7, 10 min after the sauna exit during recovery.

No significant difference was observed between dry and mist saunas in systolic $(\mathrm{p}=0.06)$ and diastolic $(\mathrm{p}=$ 0.13 ) pressures.

\subsection{Changes in Heart Rate (Figure 2)}

Significant increases from the baseline level in heart rate were observed from $1 \mathrm{~min}$ after the sauna entry in dry sauna bathing to the end of the recovery. In mist sauna bathing, heart rate change was less. It showed sig-

Table 1. Changes in blood cell count before and after dry and mist saunas.

\begin{tabular}{|c|c|c|c|c|c|c|c|}
\hline \multicolumn{8}{|c|}{ Changes in blood count before and after saunas } \\
\hline & \multicolumn{2}{|c|}{$\mathrm{RBC}\left(\times 10^{4} / \mu 1\right)$} & \multicolumn{2}{|c|}{$\operatorname{Hgb}(\mathrm{g} / 100 \mathrm{ml})$} & \multicolumn{2}{|c|}{$\operatorname{Hct}(\%)$} & \multirow{2}{*}{$\% \mathrm{PV}$ change $(\%)$} \\
\hline & pre-sauna & post-sauna & pre-sauna & post-sauna & pre-sauna & post-sauna & \\
\hline Dry sauna & $510 \pm 21$ & $528 \pm 21^{*}$ & $15.3 \pm 0.5$ & $15.9 \pm 0.5$ & $45.4 \pm 1.7$ & $46.9 \pm 1.5^{*}$ & $-5.9 \pm 1.9$ \\
\hline Mist sauna & $484 \pm 12$ & $489 \pm 14$ & $14.6 \pm 0.3$ & $14.8 \pm 0.3$ & $43.3 \pm 0.8$ & $43.8 \pm 0.9$ & $-2.0 \pm 1.2^{\dagger}$ \\
\hline
\end{tabular}

Table 2. Changes in stress-related hormones before and after saunas.

\begin{tabular}{|c|c|c|c|c|c|c|}
\hline \multicolumn{7}{|c|}{ Changes in stress-related hormones before and after saunas } \\
\hline & \multicolumn{2}{|c|}{ Noradrenalin $(\mathrm{pg} / \mathrm{ml})$} & \multicolumn{2}{|c|}{ Vasopressin (pg/ml) } & \multicolumn{2}{|c|}{ Cortisol (pg/ml) } \\
\hline & pre-sauna & post-sauna & pre-sauna & post-sauna & pre-sauna & post-sauna \\
\hline Dry sauna & $361 \pm 51$ & $485 \pm 54^{*}$ & $3.5 \pm 1.0$ & $4.3 \pm 1.2^{*}$ & $13.8 \pm 3.0$ & $13.8 \pm 3.5$ \\
\hline Mist sauna & $348 \pm 50$ & $444 \pm 65^{* *, \dagger}$ & $5.3 \pm 0.8$ & $6.4 \pm 1.2^{*}$ & $12.7 \pm 3.6$ & $11.7 \pm 2.6$ \\
\hline
\end{tabular}

${ }^{*}: \mathrm{p}<0.05,{ }^{* *} \mathrm{p}<0.01$, vs. pre-sauna. ${ }^{\dagger}: \mathrm{p}<0.05$, vs. dry sauna.

Table 3. Changes in plasma free fatty acids and plasma osmolarity before and after saunas.

\begin{tabular}{cccc}
\hline & \multicolumn{2}{c}{ Changes in plasma free fatty acids and osmolarity before and after saunas } \\
\hline & \multicolumn{2}{c}{ Free fatty acids $(\mathrm{mEq} / \mathrm{l})$} & \multicolumn{2}{c}{ Plasma osmolarity $(\mathrm{mOSM} / \mathrm{kgh})$} & pre-sauna & post-sauna & $281 \pm 1.3$ \\
\hline pry sauna & $0.20 \pm 0.08$ & $0.24 \pm 0.09^{*}$ & $284 \pm 1.1$ \\
Mist sauna & $0.24 \pm 0.08$ & $0.44 \pm 0.10^{*},+$ & $285 \pm 1.3$ \\
\hline
\end{tabular}

${ }^{*}: \mathrm{p}<0.05$, vs. pre-sauna. ${ }^{\dagger}: \mathrm{p}<0.05$, vs. dry sauna. 


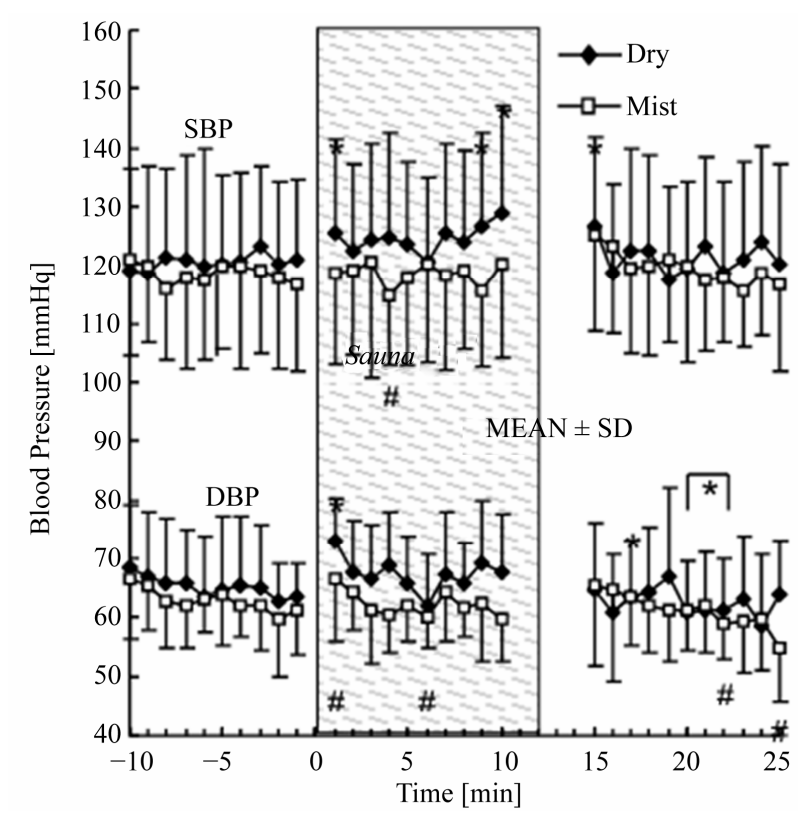

Figure 1. Changes in blood pressure before (baseline), during and after sauna bathing. Systolic (upper lines) and diastolic (lower lines) blood pressures are shown in dry $(\diamond)$ and mist ( $\square)$ sauna bathings. SBP: dry vs. mist, $\mathrm{p}<0.1$, DBP: dry vs. mist, $\mathrm{p}<0.2$, by repeated measures ANOVA. *: dry vs. baseline, \#: mist vs. baseline, $\mathrm{p}<0.05$ by paired $t$ test.

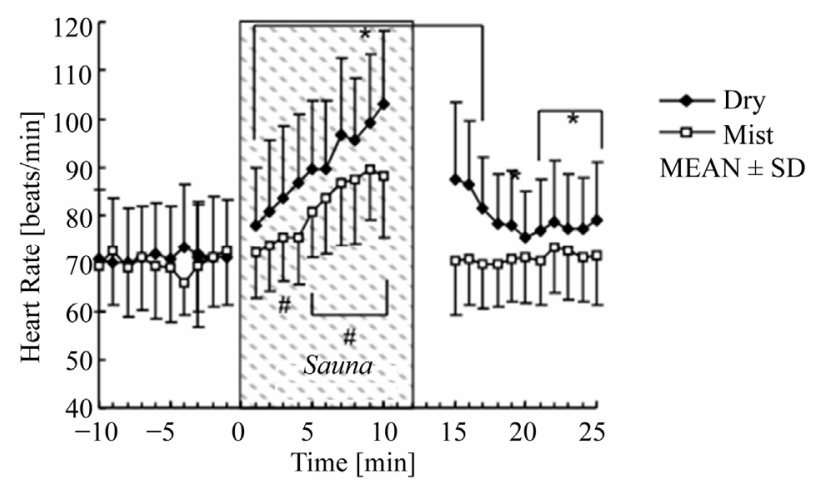

Figure 2. Changes in heart rate before (baseline), during and after sauna bathing. Heart rate (beats/min) in dry sauna $(\bullet)$ was significantly higher from that of mist sauna ( $\square$ ) bathings. Dry vs. mist, $\mathrm{p}<0.01$ by repeated measures ANOVA. *: dry vs. baseline, \#: mist vs. baseline $\mathrm{p}<0.05$ by paired $t$ test.

nificant increase in 3,5-10 min after the sauna entry while it return to the baseline level after sauna exit to the end of the recovery.

A significant difference was denoted in heart rate between dry and mist sauna bathing. Heart rate change was $32 \pm 10 \mathrm{bpm}$ in dry sauna, and $18 \pm 6 \mathrm{bpm}$ in mist sauna, which shows a significant difference $(\mathrm{p}<0.05)$.

\subsection{Changes in Averaged Skin Temperature (Figure 3)}

Averaged skin temperature increased from 1 min after

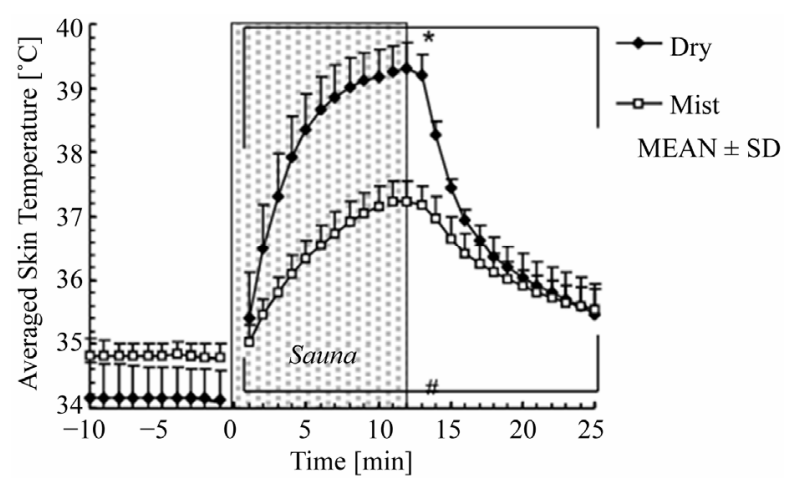

Figure 3. Changes in averaged skin temperature before (base- line), during and after sauna bathing. Averaged skin tempera- ture by Ramanathan's formula in dry sauna $(\bullet)$ bathing showed significantly higher than that in mist sauna (口) $(\mathrm{p}<0.01$ by repeated measures ANOVA). *: dry vs. baseline, \#: mist vs. baseline $\mathrm{p}<0.05$ by paired $t$ test.

the sauna entry in both dry and mist sauna bathing, and the increase was continued to the end of the recovery.

A significant difference between dry and mist saunas were observed by ANOVA ( $<<0.01$ ), and averaged skin temperature rise was $4.7^{\circ} \mathrm{C} \pm 0.9^{\circ} \mathrm{C}$ for dry and $2.3^{\circ} \mathrm{C} \pm$ $0.7^{\circ} \mathrm{C}$ for mist sauna.

\subsection{Changes in Tympanic Temperature (Figure 4)}

Tympanic temperature measured as the core temperature increased significantly from the baseline level $1 \mathrm{~min}$ after the dry sauna entry, and 2 min after the mist sauna entry.

A significantly difference between dry and mist saunas were denoted by ANOVA $(p<0.01)$, and the increase from the baseline was $0.88^{\circ} \mathrm{C} \pm 0.35^{\circ} \mathrm{C}$ in dry, and $0.45^{\circ} \mathrm{C} \pm 0.11^{\circ} \mathrm{C}$ in mist sauna.

\subsection{Changes in Skin Blood Flow and Sweating (Figures 5 and 6)}

Skin blood flow by laser Doppler flowmetry increased significantly from the baseline level $1 \mathrm{~min}$ after in the dry sauna entry, and 1 min after the mist sauna entry, and the increase continued to the end of the recovery. No significant difference was observed between dry and mist sauna bathings by ANOVA $(\mathrm{p}<0.2)$. The increase of skin blood flow from the baseline level was $14.9 \pm 7.0$ $\mathrm{ml} /(\mathrm{min} \cdot 100 \mathrm{~g}$ tissue $)$ in dry, and $12.6 \pm 5.2 \mathrm{ml} /(\mathrm{min} \cdot 100$ $\mathrm{g}$ tissue) in mist sauna bathings.

Sweat rate increased significantly from the baseline level 2 min after the dry sauna entry, and 1 min after the mist sauna entry. These increases continued to the end of the recovery. A significant difference was shown between total sweating volumes in dry and mist sauna bathings ( $\mathrm{p}$ $<0.01$ ), and the total sweat volume was $262 \pm 17 \mathrm{~g}$ in dry, and $177 \pm 34 \mathrm{~g}$ in mist sauna bathing for $10 \mathrm{~min}$. 


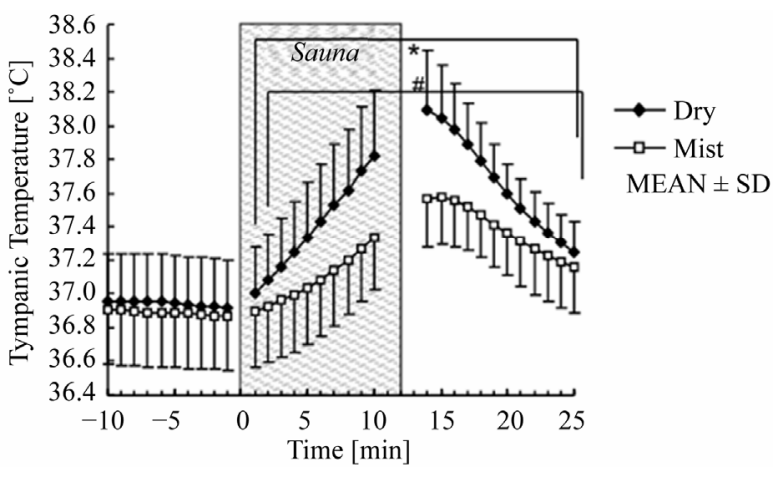

Figure 4. Changes in tympanic temperature before (baseline), during and after sauna bathing. Tympanic temperature was significantly higher in dry sauna $(\bullet)$ than in mist sauna ( $\square$ ) bathings ( $<0.01$, by repeated measures ANOVA). *: dry vs. baseline, \#: mist vs. baseline, $\mathrm{p}<0.05$ by paired $t$ test.

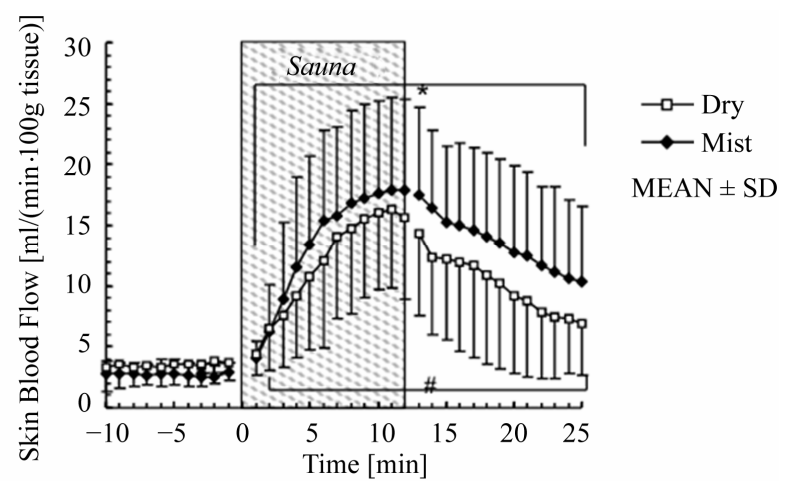

Figure 5. Changes in skin blood flow before (baseline), during and after sauna bathing by laser Doppler flowmetry at the forearm. There is a tendency of difference between skin blood flow at the forearm in dry $(\checkmark)$ and mist $(\square)$ sauna bathings but not significant $(0.1<\mathrm{p}<0.2$, by repeated measures ANOVA). *: dry vs. baseline, \#: mist vs. baseline, $\mathrm{p}<0.05$ by paired $t$.

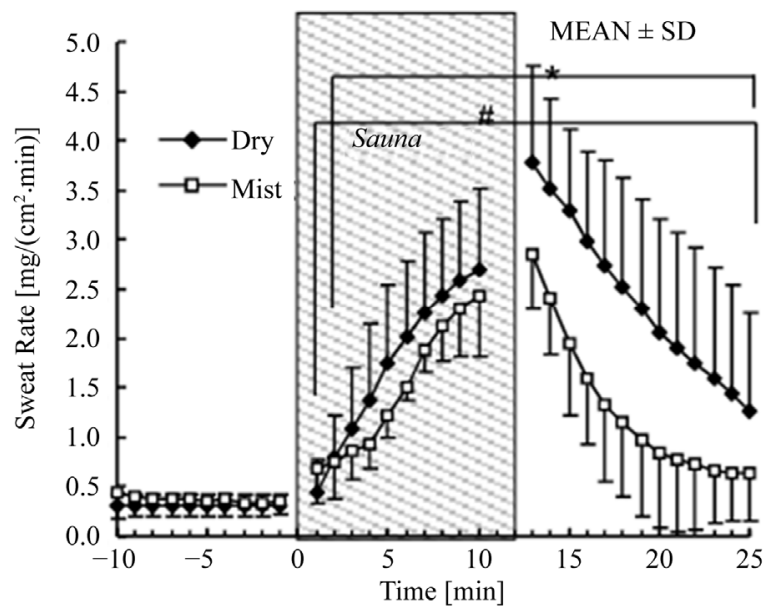

Figure 6. Changes in sweat rate at the dorsum manus before (baseline), during and after sauna bathing by ventilated capsule method. Dry sauna $(\diamond)$ induced more sweat rate than mist sauna $(\square)(\mathrm{p}<0.01$, repeated measures ANOVA). *: dry vs. baseline, \#: mist vs. baseline, $\mathrm{p}<0.05$ by paired $t$ test.

\subsection{Skin Temperature and Sweating Change against Tympanic Temperature Rise (Figure 7)}

In order to standardize the changes in peripheral parameters against the core temperature change between the dry and mist sauna bathings, changes in skin blood flow and sweat rate against tympanic temperature rise were examined. The times for increase in core temperature rise of $0.1^{\circ} \mathrm{C}, 0.2^{\circ} \mathrm{C}$, and $0.3^{\circ} \mathrm{C}$ were $2.1 \pm 1.3 \mathrm{~min}$, $3.6 \pm 2.1 \mathrm{~min}$, and $4.6 \pm 2.1 \mathrm{~min}$ respectively in dry sauna bathing, and $4.0 \pm 1.9 \mathrm{~min}, 6.1 \pm 1.6 \mathrm{~min}$, and 7.9 $\pm 1.7 \mathrm{~min}$ in mist sauna bathing, and there exists a significant difference between dry and mist $(\mathrm{p}<0.01)$.

The increases in skin blood flow per core temperature rise between dry and mist sauna were not significantly different in core temperature rise of $0.1^{\circ} \mathrm{C}$ and $0.2^{\circ} \mathrm{C}(\mathrm{p}=$ 0.2 and $\mathrm{p}=0.11$ respectively), while that in core temperature rise of $0.3^{\circ} \mathrm{C}$ was significantly greater in mist sauna bathing $(\mathrm{p}<0.05)$. There were no significant difference in the increase in sweat rate per core temperature rise between mist and dry sauna bathings.

\section{DISCUSSION}

In the present study, we compared the effect of dry and mist sauna bathings on cardiovascular and thermoregulatory function in seven young men in order to examine the hypothesis that mist sauna bathing is to provide more effective sweating and vasodilating (thermoregulatory) function while less influence on cardiovascular function than dry sauna bathing in humans.

As the result, the thermal influence on cardiovascular function was greater in dry sauna because there was a tendency of systolic blood pressure rise $(0.05<\mathrm{p}<0.1)$ only in dry sauna, and it continued to the exit. Heart rate change was also larger in the dry sauna significantly, and in the latter half of the sauna, the increase in heart rate plateaued in mist while that in dry sauna continued to increase to the end of the exit.

The phasic effect of dry and mist sauna bathings were denoted by significant blood pressure rise on entry to the sauna, but the effect soon disappeared because this blood pressure rise was caused by the sudden thermal environmental change, leading to the heart rate increase and vasoconstriction. Increase in blood pressure in the course of dry sauna bathing was also reported by Watanabe et al. [7] in $90^{\circ} \mathrm{C}-100^{\circ} \mathrm{C}$ dry sauna bathing. We set the lower temperature of dry sauna bathing not to provide a thermal stress to the subjects, however, thermal stress still exists even in $70^{\circ} \mathrm{C}$ dry sauna bathing.

In spite of no significant difference (although $\mathrm{p}<0.1$ ) in blood pressure between dry and mist sauna bathings, heart rate increase exhibited a significant difference between dry and mist sauna bathings. This change may be 

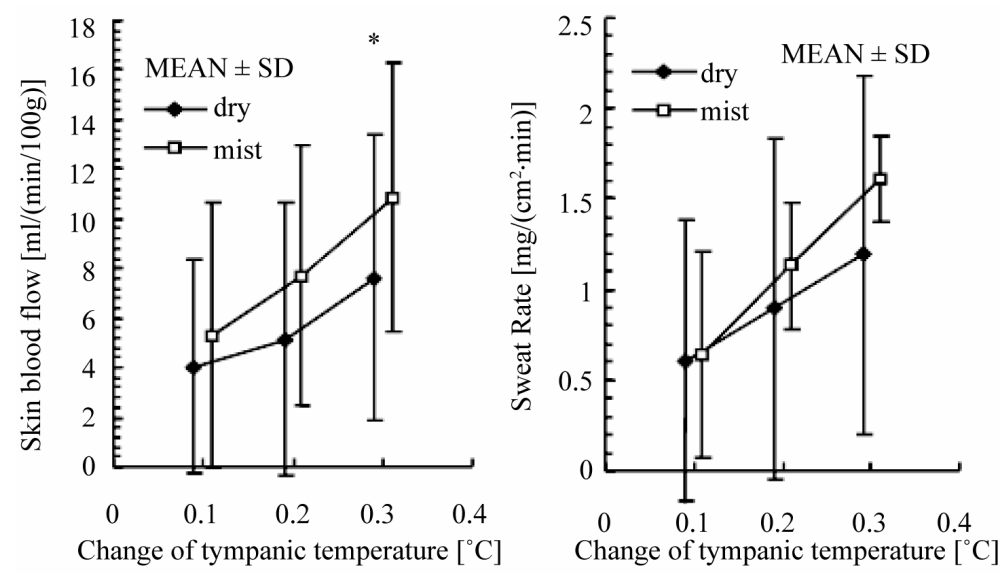

Figure 7. Changes in skin blood flow (upper panel) and sweat rate (lower panel) against Tty changes by $0.1^{\circ} \mathrm{C}, 0.2^{\circ} \mathrm{C}$, and $0.3^{\circ} \mathrm{C}$ from the baseline. The data were calculated from the average of skin blood flow and sweat rate at the increase by $0.1^{\circ} \mathrm{C}, 0.2^{\circ} \mathrm{C}$, and $0.3^{\circ} \mathrm{C}$ from the baseline.

attributed to the young aged subjects in the present study. Well compliant blood vessels would buffer the blood pressure change.

Tty increased with the rise in skin temperature in both dry and mist sauna bathings, and the increase was significantly greater in dry sauna, showing that the thermal stress was greater in dry sauna as observed in heart rate change.

Skin blood flow tended to be increased more in dry sauna than in mist sauna $(0.1<\mathrm{p}<0.2)$, and total sweat volume was more obtained in dry sauna than in mist sauna. The hematocrit change was significantly more increased in dry sauna than in mist sauna. These results suggested that mist sauna dilated skin vessels more, accelerated sweating more, and increased the Tty more, however, when it is standardized as change per Tty change, the thermoregulatory effect has turned to be greater in mist sauna $\left(\mathrm{RT}=40^{\circ} \mathrm{C}, \mathrm{RH}=70 \%\right.$ ) than dry sauna $\left(\mathrm{RT}=70^{\circ} \mathrm{C}, \mathrm{RH}=16 \%\right)$ bathings. This reverse might be attributed that heat loss of mist sauna bathers is dependent on vasodilatation dominantly than evaporation by sweating due to wet skin by hidromeiosis as previously reported [8]. It means that mist sauna induces vasodilative and sweating functions more effectively than dry sauna.

The thermal stress during saunas was greater in dry sauna than in mist assessed by the release of noradrenalin although the vasodilative response from the dry and mist saunas were not significantly different according to laser Doppler flowmetry. The total sweat production during saunas larger in dry sauna than mist sauna. Therefore it is likely that hypovolemia (reduction in circulatory blood volume calculated from the hematocrit) as well as dehydration (calculated from the body weight loss after saunas) in dry sauna was induced by this hyperhidrosis due to higher thermal stress by dry sauna than by mist sauna. However, this thermal stress seemed to be not so strong to change the plasma osmolarity. Therefore the increase in vasopressin might be attributed to thermal stress, and the duration of thermal stress for $10 \mathrm{~min}$ seemed not to be so long to induce the difference in vasopressin secretion between dry and mist saunas.

In conclusion, mist sauna provides less heat stressful environment than dry sauna, inducing less blood pressure rise, less heart rate increase, less dehydration by sweating, less circulatory plasma volume reduction, and more efficacy in vasodilatation and sweating. This means mist sauna is more tender and safer sauna bathing system to the circulatory function than dry sauna with more efficiency on thermoregulatory function.

In the present study, since we aimed to clarify the difference of sauna bathing under moderate heat stress, we compared mist and dry saunas with different room temperature and different relative humidity. Therefore, we could not determine whether the changes were dependent on temperature or humidity, however, it provided important findings on the difference between mist and dry saunas under mild condition.

\section{REFERENCES}

[1] Ahonen, E. and Nousiainen, U. (1988) The sauna and body fluid balance. Annals of Clinical Research, 20, 257261.

[2] Leppaluoto, J. (1988) Human thermoregulation in sauna. Annals of Clinical Research, 20, 240-243.

[3] Ueda, M. (1988) Sauna bathing. Japanese Association of Physical Medicine, Balneology and Climatology, 52, 2733.

[4] Vuori, I. (1988) Sauna bather's circulation. Annals of Clinical Research, 20, 249-256.

[5] Sudoh, M., Yokota, K., Abe, S., et al. (1996) Effect of 
mist and dry saunas on human body. Japanese Journal of Aerospace \& Environment Medicine, 33, 294.

[6] Watanabe, I., Agishi, Y., Noro, H., et al. (1993) Difference of body temperature response between dry and mist saunas. Biomedical Thermology, 13, 146-150.

[7] Watanabe, I., Agishi, Y., Noro, H., et al. (1994) Difference in circulatory function between dry and mist saunas. Rinsho Taion, 14, 35-42.

[8] Miwa, C., Iwase, S. and Mano, T. (1999) Mist heat effects on thermoregulatory function during bathing at $41^{\circ} \mathrm{C}$ in humans. The Autonomic Nervous System, 36, 478-484.

[9] Kondo, Y. (1985) The application of far infrared ray heating. Dennetsu, 22, 80-86.

[10] Dubois, D. and Dubois, E.F. (1916) A formula to estimate the approximate surface area if height and weight be known. Archives of Internal Medicine, 17, 863-871. doi:10.1001/archinte.1916.00080130010002

[11] Van Beaumont, W. (1872) Evaluation of hemocencentration from hematocrit measurements. Journal of Applied Physiology, 33, 55-61.

[12] Ramanathan, N.L. (1964) A new weighting system for mean skin temperature of the body. Journal of Applied Physiology, 19, 531-533. 